\title{
Öğretmen Adaylarının Düșünme Becerileri: Yanal Düşünme ile Bilişsel Esneklik Arasındaki İlișki*
}

\author{
Çiğdem ŞAHIN-TAȘKIN ${ }^{1}$, Hanife ESEN-AYGÜN²
}

\begin{abstract}
Öz: Bireyin bir amaca ulaşabilmek için bilinçli bir şekilde düşünme kapasitesini ifade eden düşünme becerileri öğretmenlerin sınıf içinde karşılaşmış oldukları sorunlara alternatif çözüm yolları üretmeleri bakımından önem taşımaktadır. Bu araştırmada, Okul Öncesi Öğretmenliği ve Sınıf Öğretmenliği lisans programlarında öğrenim gören adayların yanal düşünmeye yönelik eğilimleri ile bilişsel esneklik becerileri arasındaki ilişkiyi belirlemek amaçlanmıştır. Araştırma, ilişkisel tarama modeli ile tasarlanmıştır. Araştırmada veriler Semerci (2016) tarafından geliştirilen Yanal Düşünme Eğilimi Ölçeği ile Sapmaz ve Doğan (2013) tarafından geliştirilen Bilişsel Esneklik Envanteri kullanılarak toplanmıştır. Araştırmanın örneklemini 457 öğretmen adayı oluşturmaktadır. Verilerin analizi sonucunda adayların yanal düşünme eğilimlerinin, cinsiyet, anabilim dalı, sınıf düzeyi ve ebeveynlerin öğrenim durumuna göre anlamlı farklılık göstermediği görülmüştür. Bununla birlikte, öğretmen adaylarının yanal düşünme eğilimleri ile bilişsel esneklik becerileri arasında pozitif yönde ve yüksek düzeyde ilişki olduğu belirlenmiştir. Bu doğrultuda, öğretmen eğitiminde yanal düşünme eğitimine önem verilmesi öğretmen adaylarının bilişsel esneklik becerilerini geliştirmelerini destekleyecektir. Böylece, mesleğe başladıklarında karşılaştıkları farklı durumlarda alternatif çözüm yollarını kullanmalarına yardımcı olacaktır.
\end{abstract}

Anahtar Sözcükler: Yanal Düşünme Eğilimi, Bilişsel Esneklik, Öğretmen Adayı

\section{Preservice Teachers' Thinking Skills: The Relationship between Their Lateral Thinking and Cognitive Flexibility Skills}

\begin{abstract}
Expressing the capacity of the individual to think consciously to achieve a goal is important for teachers to produce alternative solutions to the problems they face in their classroom. This research aims to examine the relationship between lateral thinking tendencies and cognitive flexibility skills of pre-service teachers enrolled in preschool and primary education programs. The data were collected through the Lateral Thinking Disposition Scale developed by Semerci (2016) and the Cognitive Flexibility Inventory adapted by Sapmaz and Doğan (2013). 457 pre-service teachers participated in the research. The data analysis indicated that there was no significant difference in the pre-service teachers' lateral thinking dispositions regarding gender, department, class level, and education level of parents. However, there was a positive correlation between the pre-service teachers' lateral thinking dispositions and cognitive flexibility skills. In this context, it was determined that emphasizing lateral thinking in teacher education would support pre-service teachers to develop their cognitive flexibility skills and therefore help them use alternative solutions in different situations they encounter when they start their profession.
\end{abstract}

Keywords: Lateral Thinking Tendency, Cognitive Flexibility, Pre-Service Teachers

\footnotetext{
* Bu çalışmanın bir bölümü, The 4th International Higher Education Studies Conference'da "Öğretmen adaylarının yanal düşünme ile bilişsel esneklik becerileri arasındaki ilişkinin incelenmesi" başlığ ile sözlü bildiri olarak sunulmuştur.

1 Çanakkale Onsekiz Mart Üniversitesi, Eğitim Fakültesi, Temel Eğitim Bölümü, Çanakkale, Türkiye, e-posta: csahin@comu.edu.tr, ORCID: https://orcid.org/0000-0002-6341-5380

2 Çanakkale Onsekiz Mart Üniversitesi, Eğitim Fakültesi, Eğitim Bilimleri Bölümü, Çanakkale, Türkiye, e-posta: hanifeesen@comu.edu.tr, ORCID: https://orcid.org/0000-0001-9363-7083
} 
Düşünme becerileri, bireyin bir amaca ulaşabilmek için bilinçli bir şekilde düşünme kapasitesini ifade eder (Fisher, 2010). Bireylerin çeşitli düşünme biçimlerinin benzer ve farklı yönleri bulunduğu anlaşılmaktadır. Gelecekte pek çok farklı öğrenci ve bu öğrencilerin farklı düşünme biçimleri ile karşı karşıya kalacak olan öğretmen adaylarının düşünme biçimlerini etkin olarak kullanmasının mesleki yeterliği açısından önemli olduğu düşünülmektedir. Bu araştırmada öğretmen adaylarının yeni fikirler üretme ile ilgili olan yanal düşünme eğilimleri ve yeni karşılaşılan bir duruma alternatif üretme biçimleri olan bilişsel esneklik becerileri incelenmiştir. Yanal düşünme ve bilişsel esneklik becerileri çeşitli sorunlar karşısında farklı yolları görebilme, bunun yanında sorunlar için hızlı ve etkili çözümler üretme becerisi ile ilgilidir (De Bono, 1970; Hill, 2008; Martin ve Anderson, 1998). Öğretmenler, farklı gelişimsel özellikteki çocukların bulunduğu bir sınıfta her gün çeşitli problemler ile karşı karşıya gelmektedir (Evrekli ve diğerleri 2011). Yanal düşünme ve bilişsel esnekliği etkin biçimde kullanma öğretmenlere sınıf içinde karşılaşmış olduğu sorunların etkili çözümünde fayda sağlamaktadır (Lawrence ve Xavier, 2013; Semerci, 2017). Yanal düşünme ve bilişsel esneklik kavramlarına ilişkin detaylı açıklamalar aşağıdaki gibidir.

\section{Yanal Düşünme}

İnsan beyni, sol yarımkürede gerçekleşen dikey ve sağ yarımkürede gerçekleşen yanal düşünme biçimlerine sahiptir (Wonder ve Donovan, 1988). Yeni algılar ve fikirler üretme ile ilgili olan yanal düşünme kavramı ilk kez 1967 yılında De Bono tarafından kullanılmıştır (Bala, 2014). De Bono (1992) yanal düşünmeyi şema değiştirme ve bir duruma farklı açılardan bakabilme becerisi olarak tanımlamaktadır. Hernandez ve Varkey (2008) Bono'nun bu tanımını bir adım öteye taşıyarak yanal düşünmeyi mevcut şemanın yeniden inşa edilmesi ve hayal gücünün katkısı ile yeni fikirler üretme becerisi olarak tanımlamaktadır. Fisher (2010) ise bu görüşleri esas alarak, yanal düşünmeyi yaratıcı düşünmenin bir türü olarak tanımlamıştır. Ancak, De Bono (1970) yaratıcı düşünmeyi yanal ve dikey düşünmenin bir sentezi olarak açıklamaktadır. Bu doğrultuda, yanal düşünme özgün bakış açıları üretme bakımından yaratıcı düşünme ile benzerlik göstermektedir. Ancak, aynı anda farklı bakış açılarına yönelebilmesi sayesinde geleneksel düşünme biçimlerinden farklılık gösterir. Benzer şekilde, yanal düşünme yaratıcılığın yanında içgörü ve mizah kapasitesi ile ilgili olmakla birlikte kasıtlı olması bakımından bu üç kavramdan ayrılır (Lawrence ve Xavier, 2013). Bu durumda, yanal düşünme kişinin yeni bir durum karşısında alternatif çözüm yollarına yönelmesi olarak tanımlanabilir. Yanal düşünme kişinin birden çok bakış açısından olayları ele alabilmesini gerektirir (Yıldız ve Yılmaz, 2020). Bu doğrultuda, yanal düşünme eğiliminde olan bireyler yeni bakış açıları ortaya koyma, olasılıklar üzerinde düşünme ve parçadan bütüne akıl yürütme gibi becerileri kullanmaktadır (De Bono, 1990). Bu açıdan, yanal düşünme eğilimi bilişsel esnekliğin yeni durumlara yeni çözümler öneren alternatif üretme boyutu kapsamında değerlendirilebilir.

\section{Bilişsel Esneklik}

Bilişsel esneklik bireyin karşılaşılan bir duruma ilişkin alternatif yolların farkında olması, duruma uyum sağlamaya istekli olması ve esnek olma konusunda özyeterliğe sahip olması ile açıklanmaktadır (Martin ve Anderson, 1998). Bu tanım ayrıntılı olarak açıklandığında, bilişsel esnekliğin iletişime ilişkin yeterliğin bir ögesi olarak ele alındığı görülmektedir. Duruma uyum sağlamaya karşı isteklilik ise bireylerin farklı durumlarla karşılaştıklarında iletişimde alternatif yolları denemelerini ve o duruma ait şartların gerektirdiği ihtiyaçları karşılamak amacıyla davranışlarını düzenlemelerini içerir. Bilişsel esneklik becerisine sahip olanlar birçok alternatifi gözden geçirerek çözüm arayan bireylerdir (Alper ve Deryakulu, 2010). Yanal düşünme ve bilişsel esnekliğin alanyazındaki tanımlarından hareketle, her ikisinin de bireyden alternatif çözüm yolları hakkında düşünmesini istediği anlaşılmaktadır (De Bono, 1970; Martin ve Anderson, 1998). Buna ek olarak, yanal düşünmede bireyin alternatiflere ulaşmada kasıtlı, bilişsel esneklikte ise istekli bir eğilimi söz konusudur (Hill, 2008; Lawrence ve Xavier, 2013; Martin ve Anderson, 1998). Bu bilgilerden hareketle, yanal düşünme ve bilişsel esneklik kavramları arasındaki ilişki olduğu düşünülmektedir. Günümüzde öğrencilerin yaratıcı düşünme becerilerini kullanmaları istenmektedir (Ülger ve İmer, 2013). Öğretmen adaylarından ise öğrencilerin düşüncelerini harekete geçirerek aktif düşünmelerini sağlama sorumluluğunu üstlenmeleri beklenmektedir (Lawrence ve Xavier, 2013). Bu sebeple, öğretmen adaylarının yanal düşünme becerileri hakkında farkındalık kazanması ve bu becerileri kullanabilmesi önem 
kazanmaktadır. Alanyazın, yanal düşünme ve yanal düşünmenin eleştirel düşünme gibi bazı düşünme becerileri ile arasındaki ilişki üzerine sınırlı sayıda çalışma bulunduğuna işaret etmektedir (Baysal ve diğerleri, 2016; Evin-Gencel, 2018; Yılmaz, 2017). Bu çalışmalardan elde edilen bulgular öğretmenlerin kendilerini yanal düşünme bakımından yetersiz gördüklerini (Baysal, Çarıkçı ve Yaşar, 2016); bununla beraber öğretmen adaylarının yanal düşünme eğilim düzeylerinin orta (Evin-Gencel, 2018) ve yüksek olduğunu (Yılmaz, 2017) göstermektedir. Bulgular ayrıca öğretmen adaylarının yanal düşünme eğilimleri ile eleştirel düşünme eğilimleri arasında pozitif yönde ve anlamlı bir ilişki olduğunu belirtmektedir. Bu bulgular, öğretmen adaylarının yanal düşünme eğilimlerinin daha detaylı incelenmesinin gerekliliğini vurgulamaktadir.

Günümüzde öğretmenlerden sürekli gelişime açı bireyler olmaları beklenmektedir (Öğretmen Yetiştirme Genel Müdürlüğü, 2017). Buna ek olarak, öğretmenlerden öğrencilerine yalnızca belirli bir içeriği aktaran kişi olmaktan çok onlara rehberlik etmeleri ve öğretme-öğrenme sürecini etkili bir biçimde düzenlemeleri beklenmektedir. Bu durum, öğretmenlerin sorun çözme becerisine sahip olmaları gerektiğini ve öğrencilerin içinde bulunduğu öğrenme düzeyini ve koşulları etkili bir biçimde değerlendirmelerini gerektirir. Bu sebeple, günümüz öğretmenlerinin bir durum ile karşılaştıklarında bu durumun nedenleri ve çözüm yollarını aramaları, karşılaştıkları durum karşısında kendini sorun çözebilecek olgunluğa erişmiş hissetmeleri ve karşılaştıkları yeni durumlar karşısında esnek davranmalarında gerekli olan bilişsel esneklik becerilerini (Martin ve Anderson, 1988) ve özgün düşünme yollarının işe koşulduğu yanal düşünme becerilerini kullanmalarını gerekli hale getirir. Bu doğrultuda, öğretmen adaylarının yanal düşünme eğilimleri ile bilişsel esneklik becerileri arasındaki ilişkinin belirlenmesi, öğretmen adaylarının düşünme becerilerinin ne düzeyde olduğu ve nasıl geliştirilebileceği hakkında bilgiler vereceği gibi; öğrencilere nitelikli öğrenme-öğretme süreci sağlamada onlara nasıl destek olabileceğimiz konusunda da yardımcı olacaktır. Branşı ne olursa olsun, öğretmen adaylarının düşünme becerilerinin gelişmiş olmasının gelecekte öğrencilerine fayda sağlayacağı düşünülmektedir. Bununla birlikte, düşünme becerilerinin şekillenmesinde erken çocukluk ve çocukluk yıllarının kritik öneme sahip olduğu bilinmektedir (Aubrey ve diğerleri, 2012; Dağlığlu ve Çakır, 2010; Koyuncu-Şahin ve Akman, 2018). Bu bilgiler doğrultusunda, temel eğitim dönemini ifade eden okul öncesi eğitimi ve ilkokul eğitiminin çocuklarda düşünme becerilerinin gelişimine destek olma açısından önemli olduğu anlaşılmaktadır. Bu önemden hareketle, bu araştırmada, Okul Öncesi Öğretmeni ve Sınıf Öğretmeni adaylarının yanal düşünme eğilimleri ve bilişsel esneklik beceri düzeyleri belirlenerek, bu iki düşünme biçimi arasındaki ilişkiye odaklanılmıştır. Böylece, öğretmen eğitiminde, düşünme biçimlerinin önemi mesleki gelişim açısından vurgulanmıştır. Bu araştırmada elde edilen bulguların, temel eğitimde öğretimin niteliğine katkı sağlaması beklenmektedir.

\section{Araştırmanın Gerekçesi}

Araştırmanın kuramsal çerçevesinde de açıklandığı üzere, yanal düşünme bir duruma farklı açılardan bakarak yeni fikirler üretme olarak tanımlanmaktadır (De Bono, 1992; Kohn ve O'Connell, 2008). Bu durum, fikirlerin yeniden yapılandırılarak düşünmede yeni örüntüler oluşturmayı içerir (De Bono, 1970). Dolayısıyla, geleneksel düşünmeden farklılık göstermektedir. Yanal düşünme becerileri gelişmiş olan öğretmen adayları mesleğe başladıklarında alışılmışın dışında yöntemler ile çözüm üretecek düşünme araçlarını kullanacaklar ve öğrencilerini de bu şekilde düşünmeye teşvik edeceklerdir (Lawrance ve Xavier, 2013). Bilişsel esneklik ise bireylerin bilgilerini değişen durumlara ait taleplere uyarlanabilir bir biçimde farklı şekillerde yeniden yapılandırma becerisi olarak tanımlanmaktadır (Spiro ve Jehng, 1990). Yukarıda da açıklandığı gibi, bilişsel esneklik bir duruma ait farklı alternatiflerin farkındalığını ve yeni durumlara uyum sağlamada esnek davranmaya istekli olmayı gerektirir. Bu açıklamalardan yola çıkarak, öğretmen adaylarının yanal düşünme becerileri ve bilişsel esneklik düzeylerinin bilinmesi adayların mesleğe başladıklarında karşılaştıkları sorunların çözümüne ilişkin alternatiflerin farkında olmaları ve bu sorunlara yenilikçi çözümler üretmeleri bakımından ne ölçüde destekleneceğine ilişkin bilgi sağlayacaktır. Ayrıca, bu iki değişken arasındaki ilişkinin incelenmesi öğretmen adaylarının yeni durumlara uyum sağlamada esnek olma düzeylerinin yanal düşünme becerilerindeki rolü hakkında bize ipuçları verecektir. 
Alanyazın anne-baba öğrenim durumlarının onların çocuklarına olan davranışlarını etkilediğine dikkati çekmektedir. Ayrıca, farklı eğitim durumlarına sahip ailelerin çocuklarının olaylar karşısındaki davranışlarının farklılık gösterdiği anlaşılmaktadır (Eskicumalı ve Eroğlu, 2001). Bu doğrultuda, öğretmen adaylarının anne-babalarının eğitim durumları ve adayların yanal ve bilişsel esneklik düzeyleri arasındaki ilişkiyi incelemek onların olaylara bakış açıları ve karşılaştıkları sorunlara alternatif çözümleri üretmelerinde anne-baba eğitim durumunun rolü hakkında açıklayıcı bilgiler sunacaktır. Bununla birlikte, adayların sınıf düzeyleri ve öğrenim gördükleri anabilim dalları ile yanal düşünme ve bilişsel esneklik düzeyleri arasındaki ilişki aldıkları eğitimin ve düzeyinin bu değişkenleri ne ölçüde geliştirdiğine ilişkin bir bakış açısı sunacaktır.

\section{Araştırmanın Amacı}

Bu araştırmada Temel Eğitim Bölümü öğretmen adaylarının yanal düşünme eğilimleri ve bilişsel esneklik becerileri arasındaki ilişkiyi incelemek amaçlanmaktadır. $\mathrm{Bu}$ amaca yönelik araştırma soruları aşağıdaki gibidir:

1. Öğgretmen adaylarının yanal düşünme eğilimleri ve bilişsel esneklikleri ne düzeydedir?

2. Öğretmen adaylarının yanal düşünme eğilimlerinin cinsiyete göre farklılaşmakta mıdır?

3. Öğretmen adaylarının yanal düşünme eğilimleri öğrenim gördükleri anabilim dalına göre farklılaşmakta mıdır?

4. $\quad$ Öğretmen adaylarının yanal düşünme eğilimleri sınıf düzeylerine göre farklılaşmakta mıdır?

5. Öğretmen adaylarının yanal düşünme eğilimleri annenin öğrenim durumuna göre farklılaşmakta mıdır?

6. Öğretmen adaylarının yanal düşünme eğilimleri babanın öğrenim durumuna göre farklılaşmakta mıdır?

7. Öğretmen adaylarının yanal düşünme eğilimleri ve bilişsel esneklik düzeyleri arasında bir ilişki var midır?

\section{Yöntem}

\section{Araştırmanın Modeli}

$\mathrm{Bu}$ araştırma, ilişkisel tarama modeli ile tasarlanmıştır. Tarama modeli varolan bir durumu olduğu şekliyle betimlemeyi amaçlayan araştırma yaklaşımı olarak tanımlanmaktadır (Karasar, 2011). Tarama modeli, genel tarama modelleri ve örnek olay olmak üzere iki şekilde sınıflandırılır. Genel tarama modeli de kendi içinde tekil ve ilişkisel tarama modeli olarak ikiye ayrılır. Bu araştırmada kullanılan ilişkisel tarama modeli, iki ve daha çok değişken arasında birlikte değişimin varlığını belirlemeyi amaçlamaktadır $\mathrm{Bu}$ modelde, değişkenlerin birlikte değişip değişmediği, değişim varsa bunun nasıl olduğu belirlenir (Karasar, 2011). Bu araştırmanın amacı dikkate alındığında; öğretmen adaylarının yanal düşünme eğilimleri ve bilişsel esneklik becerileri arasındaki ilişkinin incelendiği görülmektedir. Bu doğrultuda ilişkisel tarama modelinin bu araştırma için en uygun model olduğu düşünülmektedir.

\section{Araştırmanın Evren ve Örneklemi}

Araştırmada örneklem Marmara bölgesinde bir devlet üniversitenin Temel Eğitim Bölümü'ndeki öğretmen adaylarından oluşturmaktadır. Veriler 2018-2019 akademik yılı bahar yarıyılında toplanmıştır. Verilerin toplanmasında basit seçkisiz örnekleme yöntemi kullanılmıştır. Basit seçkisiz örnekleme yönteminde evrendeki tüm birimler arasından rastgele seçim yapılır (Büyüköztürk ve diğerleri, 2012). Bu doğrultuda, katılımcıların her biri evrenden seçilmek için eşit şansa sahiptir. Örneklemin evreni yeterince temsil edebilmesi için \% 95'lik güven aralığı kabul edilerek örneklem büyüklügü̈ belirlenmiştir (Krejcie ve Morgan, 1970). Araştırma verilerinin toplandığı akademik yılda Temel Eğitim bölümünde yaklaşık 550 öğretmen adayı öğrenim görmektedir. Buna göre, Krejcie ve Morgan'ın (1970) örneklem büyüklüğünü 
belirmede önerdikleri formül esas alındığında 500 kişilik evren için örneklemde en az 217 katılımcının yer alması gerektiği anlaşılmaktadır. Buna dayalı olarak, araştırma evreninde yer alan katılımcılara araştırmanın genel amacı hakkında bilgi sunularak gönüllü olanların katılımı sağlanmıştır. Araştırmaya 457 öğretmen adayı katılmıştır. Katılımcılara ait demografik bilgiler Tablo 1'de sunulmuştur. .

Tablo 1. Örnekleme İlişkin Demografik Bilgiler

\begin{tabular}{lccccc}
\hline Anabilim Dalı & N & Cinsiyet & N & Sınıf düzeyi & N \\
\hline Sını Öğretmenliği & 216 & Kadın & 366 & 1 & 106 \\
\hline Okul Öncesi Öğretmenliği & 241 & Erkek & 91 & 2 & 120 \\
\hline & & & & 3 & 151 \\
\hline
\end{tabular}

Tablo 1 incelediğinde araştırmaya katılan öğretmen adaylarının 216'sının Sınıf Eğitimi ve 241'inin Okul Öncesi Eğitimi Anabilim dalında öğrenim gördüğü anlaşılmaktadır. Bununla birlikte, araştırmaya 366 kadın ve 91 erkek öğretmen adayı katılmıştır. Araştırmaya katılan öğretmen adaylarının 106'sı birinci sınıfta, 120'si ikinci sınıfta, 151'i üçüncü sınıfta ve 78'i dördüncü sınıfta öğrenim görmektedir.

\section{Veri Toplama Araçları ve Süreci}

Araştırmada veriler Semerci (2016) tarafından geliştirilen Yanal Düşünme Eğilimi Ölçeği ile Sapmaz ve Doğan (2013) tarafından uyarlanan Bilişsel Esneklik Envanteri kullanılarak toplanmıştır. Ayrıca öğretmen adaylarına ait demografik bilgiler Kişisel Bilgi Formu aracılığıyla elde edilmiştir.

Yanal Düşünme Eğilimi Ölçeği (YD) tek faktör ve 9 maddeden oluşmaktadır. Ölçekte yer alan sorular Hiç katılmıyorum(1), Çoğunlukla katılmıyorum (2), Kısmen katılıyorum (3), Çoğunlukla katıllyorum (4) ve Tamamen katılıyorum (5) şeklinde puanlanmaktadır. Ölçekten alınabilecek en yüksek puan 45 en düşük puan 9'dur. Ölçme aracında olumsuz madde bulunmamaktadır. Yanal Düşünme Eğilimi Ölçeği'nin Cronbach Alpha katsayısı Semerci (2016) tarafından 0.754 olarak hesaplanmıştır. Yapılan doğrulayıcı faktör analizi sonucunda uyum indeksleri; GFI=0.998, sd=16, Ki kare=6.744, RMSEA=0.000, CFI=1.000 olarak hesaplanmıştır. Bu durum ölçme aracının geçerli ve güvenilir olduğuna işaret etmektedir. Bu araştırma için yapılan analiz sonucunda Cronbach Alpha katsayısı .829 olarak hesaplanmıştır.

Bilişsel Esneklik Envanteri (BE), Alternatifler (13 madde) ve Kontrol (7 madde) olmak üzere iki faktör ve 20 maddeden oluşmaktadır. Ölçekte yer alan sorular Hiç uygun değil (1), Uygun Değil (2), Biraz Uygun (3), Uygun (4), Tamamen Uygun (5) şeklinde puanlanmaktadır. Ölçme aracından alınabilecek en yüksek puan 100 en düşük puan 20'dir. Ölçme aracından yer alan 5 madde tersten kodlanmaktadır. Bilişsel Esneklik Envanteri'nin Cronbach alfa güvenirlik katsayısı Doğan ve Sapmaz (2013) tarafından ölçeğin tamamı için. 90, "alternatifler" alt boyutunda .90 olarak; "kontrol alt boyutunda ise .84 olarak hesaplanmıştır. Doğrulayıc1 faktör analizi sonucunda $\chi 2=406.98, \mathrm{sd}=167, \chi 2 / \mathrm{sd}=2.44$, $\mathrm{AGFI}=0.90, \mathrm{GFI}=0.92, \mathrm{NFI}=0.96, \mathrm{RFI}=0.95, \mathrm{IFI}=0.98$, CFI=0.98, RMR $=0.052$, RMSEA $=0.054$ hesaplanmıştır. Bu araştırma için yapılan analizde Cronbach Alpha katsayısı ölçeğin tamamı için .748, alternatifler boyutu için .735 kontrol boyutu için .726 olarak hesaplanmıştır.

Sonuç olarak, Yanal Düşünme Eğilimi ve Bilişsel Esneklik Envanterinin geçerli ve güvenilir veri toplama araçları olduğu belirlenmiştir. Bu doğrultuda, öğretmen adaylarının Yanal Düşünme Eğilimleri ve Bilişsel Esneklik düzeylerinin belirlenmesinde kullanılmalarının uygun olduğu düşünülmüştür.

\section{Araştırma ile İlgili Etik Hususlar}

Araştırmaya ilişkin etik kurul izni alınmıştır. Bu kapsamda; araştırmaya katılan öğretmen adaylarına öncelikle çalışmanın amacı ve kapsamı hakkında bilgi verilmiştir. Gönüllü katılım ilkesinin sağlanması amacıyla katılımcılara araştırmanın kişisel rahatsızlık verecek nitelikte olmadığı, herhangi bir nedenden dolayı kendilerini rahatsı hissetmeleri durumunda nedenini açıklamaksızın araştırmayı yarıda bırakıp çıkmakta serbest oldukları bilgisi verilmiştir. Bununla birlikte, araştırma süresince ve sonrasında kimlik bilgilerinin gizli tutulacağı sadece araştırma amaçlı kullanılacağı katılımclara belirtilmiştir. Bu doğrultuda, araştırma kapsamında elde edilen verilerde katılımcıların kimlik bilgileri alınmamış olup; veriler 
numaralandırılarak kodlanmıştır. Ayrıca, adayların araştırmaya katılımları sırasında eğitim-öğretim faaliyetlerinin olumsuz etkilenmemesi amacıyla görüşmeler adayların ders saatleri dışında uygulanmıştır.

\section{Verilerin Analizi}

Araştırmada verilerin normal dağılıma uygunluğunu incelemek amacıyla çarpıklık ve basıklık katsayıları hesaplanmış ve ayrıca Kolmogorov-Smirnov testi uygulanmıştır. Araştırma verilerine ilişkin betimsel istatistikler ve Kolmogorov-Smirnov testi sonuçları Tablo 2 ve Tablo 3'te sunulmuştur.

Tablo 2. Betimsel İstatistikler

\begin{tabular}{|c|c|c|c|}
\hline & & İstatistik & Standart Hata \\
\hline \multirow{8}{*}{ 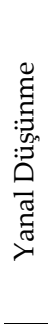 } & Ortalama & 3.76 & .02 \\
\hline & Medyan & 3.77 & \\
\hline & Varyans & .30 & \\
\hline & Standart Sapma & .55 & \\
\hline & Minimum & 2.00 & \\
\hline & Maksimum & 5.00 & \\
\hline & Çarpıklık & -.22 & .11 \\
\hline & Basıklık & .19 & .22 \\
\hline \multirow{8}{*}{ 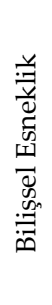 } & Ortalama & 3.61 & .01 \\
\hline & Medyan & 3.60 & \\
\hline & Varyans & .14 & \\
\hline & Standart Sapma & .37 & \\
\hline & Minimum & 2.40 & \\
\hline & Maksimum & 5.00 & \\
\hline & Çarpıklık & .17 & .11 \\
\hline & Basıklık & .29 & .22 \\
\hline
\end{tabular}

Tablo 2 incelediğinde öğretmen adaylarının Yanal Düşünme Ölçeği ve Bilişsel Esneklik Envanterine vermiş oldukları cevapların normal dağılıma uygunluğunu incelemek amacıyla çarpıklık ve basıklık katsayıları kendi standart hatalarına bölünmüştür (Tabachnick ve Fidell, 2001). Bu doğrultuda Yanal Düşünme Ölçeği için çarpıklık -1.97 basıklık +0.86 ; Bilişsel Esneklik Envanteri için çarpıklık +1.56 basıklık +1.28 olarak hesaplanmıştır. Elde edilen değerler +1.96 ila -1.96 arasında yer aldığı için veri setinin normal dağılıma uygunluk gösterdiği anlaşılmaktadır (Kalaycı, 2010). Bu araştırmada normal dağılıma uygunluğun incelenmesinde çarpıklık ve basıklık katsayılarının hesaplanmasının yanı sıra Kolmogorov- Smirnov testi uygulanmıştır. Teste ilişkin bulgular Tablo 3'teki gibidir:

Tablo 3. Kolmogorov-Smirnov Testi

\begin{tabular}{lcrr}
\hline & \multicolumn{3}{c}{ Kolmogorov-Smirnov } \\
\hline & İstatistik & sd & Sig. \\
\hline Yanal Düşünme & .08 & 457 & .45 \\
Bilişsel Esneklik & .06 & 457 & .40 \\
\hline
\end{tabular}

Tablo 3 incelediğinde Yanal düşünme (Sig. 455) ve Bilişsel esneklik (Sig. 401) için hesaplanan Sig. değeri .05 'ten büyüktür. Bu durum veri setinin normal dağılıma uygunluk gösterdiğine işaret etmektedir (Kalaycı, 2010). Hem çarpıklık ve basıklık katsayılarının kendi standart hatalarına bölünmesi sonucu elde edilen değerler hem de Kolmogorov-Smirnov testi sonucunda veri setinin normal dağılıma uygunluk gösterdiği anlaşılmaktadır. Bu doğrultuda, bu araştırma verilerinin analizinde parametrik testlerin kullanılmasının uygun olduğuna karar verilmiştir. Bu sonuçlardan hareketle, öğretmen adaylarının yanal düşünme eğilimlerinin cinsiyete ve öğrenim gördükleri anabilim dalına göre farklılaşıp farklılaşmadığını belirlemek amacıyla verilere $t$ testi uygulanmıştır. Öğretmen adaylarının yanal düşünme eğilimlerinin sınıf düzeylerine, anne ve baba öğrenim düzeylerine göre farklılaşıp farklılaşmadığını belirlemek amacıyla verilere ANOVA testi uygulanmıştır. Ayrıca, öğretmen adaylarının yanal düşünme eğilimleri ve bilişsel esneklik düzeyleri arasında ilişki olup olmadığını belirlemek için Pearson korelasyon katsayısı hesaplanmıştır. 


\section{Bulgular}

Araştırmanın bu bölümünde öğretmen adaylarının düşünme becerileri yanal düşünme eğilimleri ve bilişsel esneklik becerileri bakımından incelenmiş ve bu iki düşünme becerisi arasındaki ilişki araştırılmıştır. Araştırmadan elde edilen bulgular, öğretmen adaylarının Yanal Düşünme ölçeğine verdikleri yanıtların ortalamasının $X=3.76$ ve standart sapmasının $S s=.55$ olarak belirlendiğini göstermektedir. Öğretmen adaylarının Bilişsel Esneklik Envanterine verdikleri yanıtların ortalaması $X=3.61$ standart sapması ise $S \mathrm{~s}=.37$ olarak hesaplanmıştır. Bu bulgular, öğretmen adaylarının hem yanal düşünme eğilimlerinin hem de bilişsel esneklik becerilerinin iyi düzeyde olduğunu göstermektedir.

Çalışma kapsamında öğretmen adaylarının yanal düşünme eğilimleri ile cinsiyetleri arasındaki ilişki araştırılmıştır. Cinsiyete göre t-testinden elde edilen bulgular tablo 4 'te verilmiştir.

Tablo 4. Yanal Düşünme Ĕ̆iliminin Cinsiyete Göre t-testi Sonuçları

\begin{tabular}{lrrrrrr}
\hline Cinsiyet & $\mathrm{N}$ & Ortalama & Ss. & sd & $\mathrm{t}$ & $\mathrm{p}$ \\
\hline Kadın & 366 & 3.75 & .55 & 453 & -.626 & .53 \\
Erkek & 91 & 3.79 & .58 & & &
\end{tabular}

Tablo 4 incelediğinde öğretmen adaylarının yanal düşünme eğilimlerinin cinsiyete göre anlamlı farklılık göstermediği anlaşılmaktadır $(\mathrm{t}(453)=-.626$, p<.53). Bu bulgu, kadın ve erkek öğretmen adaylarının yanal düşünme eğilimlerinin benzer olduğuna işaret etmektedir.

İkinci araştırma sorusu kapsamında öğretmen adaylarının yanal düşünme eğilimleri ile öğrenim gördükleri anabilim dalı arasındaki ilişki incelenmiştir. Bulgular Tablo 5'teki gibidir:

Tablo 5. Yanal Düşünme Eğiliminin Anabilim Dalına Göre t-testi Sonuçları

\begin{tabular}{lrrrrrr}
\hline ABD & $\mathrm{N}$ & Ortalama & Ss. & $\mathrm{sd}$ & $\mathrm{t}$ & $\mathrm{p}$ \\
\hline SE & 241 & 3.76 & .55 & 452 & -.136 & .89 \\
OÖE & 216 & 3.76 & .55 & & & \\
\hline
\end{tabular}

Tablo 5'te yer alan bulgular incelediğinde öğretmen adaylarının yanal düşünme eğilimlerinin adayların bağlı bulundukları anabilim dalına göre farklılaşmadığı anlaşılmaktadır ( $\mathrm{t}(452)=-.136, \mathrm{p}<.89)$. Bir diğer ifade ile Temel Eğitim Bölümü öğretmen adaylarının yanal düşünme eğilim düzeylerinin benzer olduğu görülmektedir.

Öğretmen adaylarının yanal düşünme eğilimleri ile sınıf düzeyleri arasındaki anlamlı farklılı̆̆ı incelemek amacıyla verilere Levene testi uygulanmıştır (Tablo 6.).

Tablo 6. Levene Testi Sonuçları

\begin{tabular}{lrrrr}
\hline Levene İstatistiği & Sd1 & Sd2 & Sig. \\
\hline .746 & 3 & 454 & .52
\end{tabular}

Tablo 6 incelediğinde varyansların homojen olduğu anlaşılmaktadır, Sig. 525>.05. Bir diğer ifade ile veri setinin varyans analizinin temel varsayımı olan homojenlik şartını sağladığı ve ANOVA testinin uygulanabileceği anlaşılmaktadır. Bu doğrultuda, sınıf düzeyi değişkenine göre uygulanan ANOVA testinden elde edilen bulgular aşağıdaki tabloda sunulmuştur:

Tablo 7. Yanal Düşünme Ĕ̆iliminin Sınıf Düzeyi Değişkenine Göre ANOVA Testi Sonuçları

\begin{tabular}{|c|c|c|c|c|c|}
\hline & Kareler Toplamı & $\mathrm{sd}$ & Kareler Ortalaması & $\mathrm{F}$ & $\overline{\text { Sig. }}$ \\
\hline Gruplar arası & 1.35 & 3 & .45 & 1.46 & .22 \\
\hline Gruplar içi & 139.36 & 454 & .30 & & \\
\hline Toplam & 140.71 & 457 & & & \\
\hline
\end{tabular}


Tablo 7 incelendiğinde öğretmen adaylarının yanal düşünme eğilimlerinin sınıf düzeyine dikkate alındığında anlamlı farklılık göstermediği anlaşılmaktadır $(F(454)=1.469, \mathrm{p}<.222)$.

Öğretmen adaylarının yanal düşünme eğilimlerinin anne eğitim durumuna göre farklılaşıp farklılaşmadığını belirlemek amacıyla verilere öncelikle Levene testi uygulanmıştır. Levene testine ilişkin bulgular Tablo 8'deki gibidir:

Tablo 8. Levene Testi Sonuçları

\begin{tabular}{lrrr}
\hline Levene İstatistiği & sd1 & sd2 & Sig. \\
\hline 1.153 & 4 & 453 & .33
\end{tabular}

Tablo 8 incelendiğinde varyans analizi testinin temel varsayımı olan homojenlik koşulunun sağlandığ1 görülmektedir. Bu doğrultuda, veri setinin ANOVA testine uygun olduğu anlaşılmaktadır. Öğretmen adaylarının yanal düşünme eğilimleri ile anne eğitim durumları arasındaki ilişkinin incelediği ANOVA testi sonuçları Tablo 9'daki gibidir:

Tablo 9. Yanal Düşünme Eğiliminin Anne Ĕ̆itim Durumuna Göre ANOVA Testi Sonuçları

\begin{tabular}{lrrrr}
\hline & Kareler Toplamı & sd & Kareler Ortalaması & F \\
\hline Gruplar arası & 1.17 & 4 & .29 & .93 \\
Gruplar içi & 138.24 & 453 & .31 \\
Toplam & 139.42 & 457 & \\
\hline
\end{tabular}

Tablo 9'da görüldüğü üzere öğretmen adaylarının yanal düşünme eğilimleri ile anne eğitim durumları arasında anlamlı farklılık bulunmadığı anlaşılmaktadır $(\mathrm{F}(454)=.939, \mathrm{p}<.441)$.

$\mathrm{Bu}$ araştırma kapsamında incelenen bir diğer değişken öğretmen adaylarının yanal düşünme eğilimleri ile baba eğitim durumları arasındaki ilişkidir. Veri setine öncelikle Levene testi uygulanmıştır. Bulgular Tablo 10 'da yer almaktadır:

Tablo 10. Levene Testi Sonuçları

\begin{tabular}{lrrrr}
\hline Levene İstatistiği & & sd1 & sd2 & Sig. \\
\hline 3.08 & 4 & 453 & .16
\end{tabular}

Tablo 10 incelediğinde Levene testi sonuçları veri setinin ANOVA testi uygulamaya uygun olduğuna işaret etmektedir. Bu doğrultuda, uygulanan ANOVA testine ilişkin bulgular Tablo 9'deki gibidir:

Tablo 11. Yanal Düşünme Eğiliminin Baba Eğitim Durumuna Göre ANOVA Testi Sonuçları

\begin{tabular}{lrrrrr}
\hline & Kareler Toplamı & sd & Kareler Ortalaması & F & Sig. \\
\hline Gruplar arası & 1.50 & 4 & .37 & 1.21 & .30 \\
Gruplar içi & 138.31 & 453 & .30 & .37 & \\
Toplam & 139.82 & 457 & & \\
\hline
\end{tabular}

Tablo 11 incelendiğinde öğretmen adaylarının yanal düşünme eğilimleri ile baba eğitim durumları arasında anlamlı farklılık bulunmadığı anlaşılmaktadır $(F(453)=1.218, p<.302)$.

Son araştırma sorusu kapsamında öğretmen adaylarının yanal düşünme eğilimleri ile bilişsel esneklik düzeyleri arasında ilişki incelenmiştir. 
Öğretmen Adaylarının Düşünme Becerileri...

Tablo 12. Yanal Düşünme Eğilimi ile Bilişsel Esneklik Arasındaki Korelasyon Analizi Sonuçları

\begin{tabular}{|c|c|c|c|c|c|}
\hline & & YD & Alternatif & Kontrol & $\mathrm{BE}$ \\
\hline & Pearson Correlation & 1 & $.588\left(^{* *}\right)$ & $.546\left(^{* *}\right)$ & $.701\left(^{* *}\right)$ \\
\hline \multirow[t]{3}{*}{ YD } & Sig. (2-tailed) & & .000 & .000 & .000 \\
\hline & $\mathrm{N}$ & 457 & 457 & 457 & 457 \\
\hline & Pearson Correlation & $.701\left(^{* *}\right)$ & $.966\left(^{* *}\right)$ & $.901(* *)$ & 1 \\
\hline \multirow[t]{2}{*}{$\mathrm{BE}$} & Sig. (2-tailed) & .000 & .000 & .000 & \\
\hline & $\mathrm{N}$ & 457 & 457 & 457 & 457 \\
\hline
\end{tabular}

Tablo 12 incelediğinde öğretmen adaylarının yanal düşünme eğilimleri ile bilişsel esneklik becerileri arasında pozitif yönde yüksek ilişki olduğu anlaşılmaktadır ( $\mathrm{r}=.701)$. Ayrıca bilişsel esneklik kapasitenin alt boyutları olan alternatif $(\mathrm{r}=.588)$ ve kontrol $(\mathrm{r}=.546)$ faktörleri ile yanal düşünme arasındaki ilişki incelediğinde pozitif yönde orta düzeyde ilişki bulunduğu anlaşılmaktadır.

Özetle, bulgular öğretmen adaylarının hem yanal düşünme eğilimlerinin hem de bilişsel esneklik becerilerinin iyi düzeyde olduğunu göstermekle birlikte; adayların yanal düşünme eğilimlerinin cinsiyete, bağlı bulundukları anabilim dalına, sınıf düzeyine ve anne-baba eğitim durumlarına göre farklılık göstermediği anlaşılmaktadır. Bununla birlikte, öğretmen adaylarının yanal düşünme eğilimleri ile bilişsel esneklik becerileri arasındaki ilişki incelendiğinde, adayların bilişsel esneklik beceri düzeyleri arttıkça yanal düşünme eğilimlerinin de arttığı belirlenmiştir.

\section{Sonuç ve Tartışma}

$\mathrm{Bu}$ araştırmada, öğretmen adaylarının yanal düşünme eğilimlerinin çeşitli değişkenler ve bilişsel esneklik ile olan ilişkisi araştırılmıştır. Öğretmen adaylarının yanal düşünme eğilimleri ile cinsiyetleri arasındaki ilişki incelediğinde, yanal düşünme eğiliminin cinsiyet değişkeni bakımından anlamlı düzeyde farklılaşmadığı anlaşılmaktadır. Bu bulgu alanyazında öğretmen adaylarının yanal düşünme eğilimlerinin incelendiği farklı çalışmaların bulguları ile paralellik göstermektedir (Yılmaz, 2017; Karagöz, 2019; Lawrence ve Xavier, 2013). Bununla birlikte, üniversite öğrencilerinin yanal düşünme becerilerini inceleyen çalışmalarda yanal düşünmenin cinsiyete göre farklılık göstermediği anlaşılmaktadır (Semerci, 2017). Hem öğretmen adaylarının hem de diğer üniversite öğrencilerinin yanal düşünme eğilimlerini inceleyen çalışmalardaki cinsiyete ilişkin bulgulardan hareketle kadın ve erkeklerin yanal düşünme eğilimlerinin benzer olduğu söylenebilir. Cinsiyete yönelik bu bulgu, mesleki eğitimin kadın ve erkeklerin yanal düşünme eğilimlerinde farklılaşmaya neden olmadığı şeklinde yorumlanabilir.

Araştırma kapsamında öğretmen adaylarının öğrenim gördükleri bölüm ile yanal düşünme eğilimleri arasındaki ilişki incelenmiştir. Bulgular, bu araştırmaya katılan Okul öncesi ve Sınıf öğretmeni adaylarının yanal düşünme eğilimlerinin anabilim dalı değişkenine göre anlamlı farklılık göstermediğine işaret etmektedir. Bu doğrultuda, farklı öğretmen yetiştirme lisans programlarının öğretmen adaylarının yanal düşünme eğilimlerini değiştirmediği düşünülmektedir. Alanyazın incelendiğinde, sınıf öğretmeni adaylarının yanal düşünme düzeylerini inceleyen çalışmalara bazı rastlanmaktadır (Evin-Gencel, 2018; Yıldız ve Yılmaz, 2020). Bununla birlikte, okul öncesi öğretmeni adaylarının yanal düşünme eğilimlerini konu alan herhangi bir çalışmaya rastlanmamıştır. Her ne kadar Okul Öncesi Eğitimi ve Sınıf Eğitimi programları birbirinden farklı olsa da alanyazın bu programlara yerleşen öğrencilerin bazı özellikler bakımından benzerlik gösterdiğine dikkati çekmektedir (Esen-Aygün, 2019). Bu doğrultuda, bu çalışmada ulaşılan sonuç doğrultusunda Okul öncesi ve Sınıf öğretmeni adaylarının yanal düşünme düzeylerinin benzer olmasına neden olan unsurların daha detaylı incelenmesi önerilmektedir.

Bulgular öğretmen adaylarının yanal düşünme eğilimlerinin ile sınıf düzeyine anlamlı bir farklılık göstermediğini ortaya koymaktadır. Ancak, her ne kadar anlamlı düzeyde farklılık yaratmasa da birinci sınıftan dördüncü sınıfa doğru öğretmen adaylarının yanal düşünme eğilimi puan ortalamalarının arttığı görülmektedir. Öğretmen adaylarının yanal düşünme eğilimlerinin sınıf düzeyi değişkenine göre 
incelendiği çalışmalarda hem bu araştırmayı destekleyen (Karagöz, 2019) hem de bu araştırmada elde edilen bulguların aksini iddia eden bulgular olduğu görülmektedir (Yılmaz, 2017). Örneğin, Türkçe öğretmeni adaylarının yanal düşünme eğilimlerini inceleyen Karagöz'ün (2019) çalışmasında öğretmen adaylarının yanal düşünme eğilimlerinin sınıf düzeyi değişkenine göre anlamlı farklılık göstermediği anlaşılmaktadır. Bu durumun aksine, sınıf öğretmeni adaylarının yanal düşünme eğilimlerini inceleyen Yılmaz'ın (2017) çalışmasında ise öğretmen adaylarının sınıf düzeyleri arttıkça yanal düşünme eğilimlerinin arttığı görülmektedir. Öğretmen yetiştirme lisans programları incelediğinde (Yükseköğretim Kurulu [YÖK], 2018), hem Sınıf öğretmenliği lisans programı ve hem de Okul Öncesi Öğretmenliği Lisans programında birinci sınıfta derslerin önemli bir bölümü Genel Kültür derslerinden oluşurken, ikinci sinıftan itibaren Genel Kültür derslerinin yüzde olarak ağırlığının azaldığı bununla birlikte meslek bilgisi ve alan eğitimi derslerinin ağırlığının arttı̆̆ı görülmektedir. Yanal düşünmenin yaratıcılık ile ilişkisi göz önünde bulundurulduğunda (Semerci, 2017), mesleki anlamda gelişen öğretmen adaylarının yanal düşünme eğilimlerinin bu durumdan olumlu çıktılar sağladığı düşünülmektedir. Bununla birlikte, sınıf öğretmenleri ile yapılan çalışmalar öğretmenlerin kendi yanal düşünme eğilimlerini yetersiz bulduklarına işaret etmektedir (Baysal ve diğerleri 2016). Ayrıca, öğretmen eğitiminde kullanılan öğretim yöntemleri ve değerlendirme yöntemlerinin çoğunun yanal düşünmeden çok dikey düşünmeye dayandığı bilinmektedir (Lawrence ve Xavier, 2013). Yanal düşünmenin yeni fikir üretme, problem çözme, yeniden değerlendirme gibi durumlarda kullanılabileceği vurgulanmaktadır (De Bono, 1970). Ayrıca, yanal düşünmenin başarı ve zekâyı geliştirmede önemli biri rolü olduğu araştırmacılar tarafından vurgulanmaktadır (Kumari ve Aggarwal, 2012). Bu doğrultuda, öğretmen eğitiminde yanal düşünme eğilimine daha fazla önem verilmesi öğretmen adaylarının yaratıcı düşünme becerilerinin gelişmesine katkıda bulunacağı (Yetim ve Göktaş, 2004) gibi, mesleğe başladıklarında gerçekleştirecekleri öğrenme-öğretme sürecine katkıda bulunacağı düşünülmektedir.

Araştırmanın amacı dikkate alındığında, öğretmen adaylarının ebeveynlerinin öğrenim durumlarının çocuklarının yanal düşünme eğiliminde anlamlı farklılık oluşturmadığı görülmektedir. Yanal düşünme becerisinin ilişkili olduğu eleştirel düşünme becerisi, problem çözme becerisi ve bilişsel esneklik becerisi gibi beceriler ile ebeveynlerin öğrenim durumları arasındaki ilişkiyi inceleyen araştırmalar göz önünde bulundurulduğunda bu bulgunun desteklendiği görülmektedir. Örneğin, öğretmen adaylarının eleştirel düşünme düzeylerini inceleyen çalışmalarda ebeveynlerin öğrenim durumlarının anlamlı farklılık oluşturmadığı anlaşılmaktadır (Alkın-Şahin ve diğerleri, 2014; Can ve Kaymakçı, 2008; Şen, 2009). Benzer şekilde, bilişsel esneklik becerisi ile ebeveynlerin eğitim durumları arasındaki ilişkiyi inceleyen çalışmalarda da anlamlı farklılık bulunmadığı görülmektedir (Bilgin, 2009). Bu doğrultuda, öğretmen adaylarının yanal düşünme eğilimlerinin ebeveynlerinin öğrenim durumlarına göre anlamlı farklılık göstermemesinin düşünme biçimlerinin şekillenmesinde kişilik özelliklerinin baskın olmasının rol oynadığı düşünülmektedir. Araştırmaya ve öğrenmeye merakll, sorgulayan ve değişim göstermeye istekli bireylerin eleştirel düşünme, problem çözme ve yanal düşünme gibi çeşitli düşünce biçimlerine daha yatkın olduğu bilinmektedir (Aslan, 2001; Özdemir ve diğerleri, 2012).

Öğretmen adaylarının yanal düşünme eğilimleri ile bilişsel esneklik becerileri arasındaki ilişki ilk kez bu çalışma ile incelenmiştir. Bulgular, Temel Eğitim bölümünde öğrenim gören öğretmen adaylarının yanal düşünme eğilimleri ile bilişsel esneklik becerileri arasında pozitif yönde yüksek ilişki olduğunu ortaya koymaktadır. Bu durum, bilişsel esneklik düzeyleri yüksek olan öğretmen adaylarının yanal düşünme becerilerinin de yüksek olduğuna işaret etmektedir. Yanal düşünme ve bilişsel esneklik gibi düşünme becerilerinin öğrenilmesi için bu becerilerin sistematik bir yaklaşımla öğretilmesi gereklidir (Evin-Gencel, 2018). Ayrıca, öğretmen adaylarının bu becerilere ve bu becerileri mesleğe başladıklarında kullanmalarının önemine olan farkındalıklarının artırılması önem taşımaktadır. Bu doğrultuda, öğretmen adaylarının lisans eğitimleri sırasında yanal düşünme ve bilişsel esneklik becerilerini kullanmaya yönelik gerçek yaşam durumlarıyla karşı karşıya getirilmeleri bu becerileri öğrencilerinde geliştirmeleri bakımından önem taşımaktadır. Ayrıca, gelecekte öğretmen adaylarının bilişsel esneklikleri ile yanal düşünme becerileri arasındaki ilişkinin daha ayrıntılı incelenmesi; bilişsel esnekliğin yanal düşünme becerisini yordamasına ilişkin bilgiler sağlayacaktır. 
Araştırmalar bireylerin çoklu bakış açısını kullanabilmeleri için yanal düşünme eğilimine sahip olmaları gerektiğine dikkati çekmektedir (Yılmaz, 2017). Bu doğrultuda, farklı düşünme becerilerine sahip pek çok öğrenci ile karşılaşan öğretmenler, çocukların düşünme becerilerini geliştirebilmek için kendi düşünme biçimlerini gözden geçirmeli ve öğrenme ortamını buna göre düzenlemelidir (Mahyuddin ve diğerleri, 2004). Ayrıca, küçük çocuklarda yanal düşünme eğiliminin daha hızlı geliştiği bilinmektedir. Bu bilgilerden hareketle, 3-6 yaş gurubunda öğretmenlik yapacak okul öncesi öğretmeni adaylarının yanı sıra 6-11 yaş dönemi çocuklarının eğitim öğretiminde aktif rol üstelenecek olan sınıf öğretmeni adaylarının düşünme becerilerinin gelişiminin öğrencilerinin düşünme becerilerinin gelişimine katkı sağlayacağı söylenebilir. Bu doğrultuda, öğretmen adaylarının yanal düşünme becerileri ve bilişsel esneklik arasındaki ilişkiye ait farkındalıklarını ortaya koyacak çalışmaların yapılması, bu konuya ilişkin ayrıntılı bilgiler vererek hem öğretmen adaylarının hem de öğrencilerin düşünme becerilerinin geliştirilmesine yardımcı olacaktır.

Günümüzde öğretmenlerden düşünme becerilerine sahip ve bu becerileri günlük yaşamda sorun çözmede, karşılaştıkları olaylara ilişkin alternatifleri görmede ve yaratıcı olmada kullanabilen öğrenciler yetiştirmesi beklenmektedir. Düşünme becerilerini etkili bir biçimde kullanabilen öğrenciler yetiştirmek; bu becerileri etkili kullanabilen öğretmenler ile mümkündür (Lawrance ve Xavier, 2013). Bu doğrultuda, bu araştırma ile öğretmen adaylarının yanal düşünme eğilimleri ve bilişsel esneklik beceri düzeyleri arasındaki ilişki ilk defa incelenmiştir. Böylece, bu araştırma ile ilk defa öğretmen adaylarının yanal düşünme eğilimi ve bilişsel esneklik becerilerinin gelişimi hakkında bilgiler edinilmiş ve bu bilgiler sayesinde adayların mesleğe başladıklarında karşılaşacakları olaylar ve sorunlar karşısında alışılmış düşünce kalıplarının dışına ne ölçüde çıkabilecekleri hakkında ipuçlarında ulaşılmıştır. Bu kapsamda bulgular adayların karşılaştıkları olay ve durumlara ait alternatiflerin farkında oldukları ve yeni durumlara uyum sağlamaya istekli oldukları ölçüde yanal düşünme eğilimlerinin arttığını göstermektedir. Bu durum öğretmen yetiştirme programları kapsamında adayların bilişsel esneklik becerilerini ve yanal düşünme eğilimlerini artırmaya yönelik çalışmaların önemini vurgulamaktadır. Ayrıca, bu açıklamalar ışığında bu araştırmanın gelişmiş düşünme becerilerine sahip öğrenciler yetiştirmek amacıyla öğretmen adaylarının düşünme becerilerini destekleme konusunda öğretmen yetiştirme programlarına katkı sağlayacağı düşünülmektedir.

\section{Yazar(lar)ın Beyanı}

Araştırmacıların katkı oranı beyanı: Bu çalışmada, verilerin toplanması, analiz edilmesi ve makalenin yazım aşamasında araştırmacılar eşit oranda katkıda bulunmuştur.

Etik Kurul Kararı: Bu çalı̧̧ma Çanakkale Onsekiz Mart Üniversitesi Bilimsel Araştırmaları Değerlendirme Kurulu tarafindan 09.04.2019 tarihinde incelenmiş ve 68203582-044-E.1900054068 sayılı karar ile uygun görülmüştür.

Çatışma beyanı: Araştırmada yazarlar arasında ya da diğer kişi/kurum/kuruluşlarla herhangi bir çıkar çatışması bulunmamaktadir.

Destek ve teşekkür: Bu araştırma için herhangi bir kurumdan finansal destek alınmamıştır

\section{Kaynaklar}

Alkın-Şahin, S., Tunca, N., \& Ulubey, Ö. (2014). Öğretmen adaylarının eğitim inançları ile eleştirel düşünme eğilimleri arasındaki ilişki. İlköğretim Online, 13(4), 1473-1492.

Alper, A., \& Deryakulu, D. (2010). Web ortamlı probleme dayalı öğrenmede bilişsel esneklik düzeyinin öğrenci başarısı ve tutumları üzerindeki etkisi. Eğitim ve Bilim, 33(148), 49-63.

Aslan, E. (2001). Torrance yaratıcı düşünce testi'nin Türkçe versiyonu. Marmara Üniversitesi Atatürk Ĕ̆itim Fakültesi Ĕ̆itim Bilimleri Dergisi, 14(14), 19-40.

Aubrey, C., Ghent, K., \& Kanira, E. (2012). Enhancing thinking skills in early childhood. International Journal of Early Years Education, 20(4), 332-348.

Bala, S. (2014). Lateral thinking vs vertical thinking. Deliberative Research, 24(1), 25-27. 
Baysal Z. N., Çarıkçı, S., \& Yaşar, E. B. (2016). Sınıf öğretmenlerinin düşünme becerileri öğretimine yönelik farkındalıkları. Eğitimde Nitel Araştırmalar Dergisi, 5(1), 7-28.

Bilgin, M. (2009). Bilişsel esnekliği yordayan bazı değişkenler. Journal of Educational Faculty of Çukurova University, 3(36), 142-157.

Büyüköztürk, Ş., Çakmak, E. K., Akgün, Ö. E., Karadeniz, Ş., \& Demirel, F. (2017). Bilimsel araştırma yöntemleri. Pegem Akademi.

Can, Ş., \& Kaymakçı, G. (2008). Öğretmen adaylarının eleştirel düşünme eğilimleri. Education Sciences, 10(2), 66-83.

Dağlığlu, H. E., \& Çakır, F. (2010). Erken çocukluk döneminde düşünme becerilerinden planlama ve derin düşünmenin geliştirilmesi. Eğitim ve Bilim, 32(144), 28-35.

De Bono, D. (1990). Lateral Thinking: A Textbook of Creativity. Penguin Books.

De Bono, E. (1970). Lateral thinking. Harper \& Row.

De Bono, E. (1992). Serious creativity using the power of lateral thinking to create new ideas. Harper Collins.

Esen-Aygün, H. (2019). The prediction of the teaching readiness level of prospective teachers in terms of curriculum literacy. Uluslararası Ĕ̆itim Programları ve Öğretim Çalışmaları Dergisi, 9(2), 203-220.

Eskicumalı, A. \& Eroğlu, E. (2014). Ailenin sosyo-ekonomik ve eğitim düzeyleri ile çocukların problem çözme yetenekleri arasındaki ilişki. Sakarya Üniversitesi Eğitim Fakültesi Dergisi, 1, 165-189.

Evin-Gencel, İ. (2018). Simı öğretmeni adaylarının yanal düşünme eğilimleri. VIII. Uluslararası Eğitimde Araştırmalar Kongresi, 9-11 Mayıs, Manisa, Türkiye.

Evrekli, E., İnel, D., \& Türkmen, L. (2011). Sınıf öğretmeni adaylarının problem çözme becerilerinin araştırılması. Pamukkale Üniversitesi Ĕ̆itim Fakültesi Dergisi, 29(29), 167-178.

Fisher, R. (2010). Teaching thinking in the classroom. Education Canada, 47(2), 72-74.

Hernandez, J. S. \& Varkey, P. (2008). Vertical versus lateral thinking. Physician Executive, 34(3), 26.

Hill, A. (2008). Predictors of relationship satisfaction: The link between cognitive flexibility, compassionate love and level of differentiation [Yayınlanmamış doktora tezi]. Alliant International University.

Kalaycı, Ş. (2010). SPSS uygulamalı çok değiş̧kenli istatistik teknikleri (5 baskı). Asil Yayın Dağıtım.

Karagöz, B. (2019). An evaluation of pre-service turkish teachers' lateral thinking dispositions with regard to different variables. European Journal of Education Studies, 5 (6), 156-165.

Karasar, N. (2011). Bilimsel araştırma yöntemi. Ankara: Nobel Yayıncılık.

Kohn, S. E., \& O'Connell, V. D. (2008). 6 Habits of Highly Effective Teams. The Career Press.

Koyuncu-Şahin, M., \& Akman, B. (2018). Erken çocukluk döneminde düşünme becerilerinin gelişimi. Milli Ĕ̈̆itim Dergisi, 47(218), 5-20.

Krejcie, R. V., \& Morgan, D. W. (1970). Determining sample size for research activities. Educational and psychological measurement, 30(3), 607-610.

Kumari, S. \& Aggarwal, M. (2012). Intelligence and achievement as the correlates of lateral thinking of the student teachers. International Indexed \& Referred Research Journal, 5(41), 32-33.

Lawrence, A. S., \& Xavier, S. A. (2013). Lateral Thinking of Prospective Teachers. Online Submission, 1(1), 2832.

Mahyuddin, R., Pihie, Z. A. L., Elias, H., \& Konting, M. M. (2004). The incorporation of thinking skills in the school curriculum. Kajian Malaysia, 22(2), 23-33. 
Martin, M. M. \& Anderson, C. M. (1998). The cognitive flexibility scale: Three validity studies. Communication Reports, 11(1), 1-9.

Öğretmen Yetiştirme ve Genel Müdürlüğü (2017). Öğretmenlik mesleği genel yeterlikleri. Milli Eğitim Bakanlığı.

Özdemir, O., Özdemir, P. G., Kadak, M. T., \& Nasıroğlu, S. (2012). Kişilik gelişimi. Psikiyatride Güncel Yaklaşımlar, 4(4), 566-589.

Sapmaz, F., \& Dogan, T. (2013). Assessment of cognitive flexibility: reliability and validity studies of turkish version of the cognitive flexibility inventory. Ankara University, Journal of Faculty of Educational Sciences, $46(1), 143-161$.

Semerci, Ç. (2016). Developing a lateral thinking disposition (latd) scale: a validity and reliability study/yanal düşünme eğilimi (yade) ölçeğinin geliştirilmesi: geçerlik ve güvenirlik çalışması. Eğitimde Kuram ve Uygulama, 12(1), 358-371.

Semerci, N. (2017). Pedagogical formation students' dispositions toward lateral thinking. Bartın Üniversitesi Ĕ̆itim Fakültesi Dergisi, 6(1), 336-345.

Spiro, R. J., \& Jehng, J. (1990). Cognitive flexibility and hypertext: Theory and technology for the nonlinear and multidimensional traversal of complex subject matter. D. Nix, \& R. Spiro,(Eds) Cognition, education and multimedia: Exploring ideas in high technology, içinde (s.163-205). Routledge

Şen, Ü. (2009). Türkçe öğretmeni adaylarının eleştirel düşünme tutumlarının çeşitli değişkenler açısından değerlendirilmesi. Zeitschrift für die Welt der Türken/Journal of World of Turks, 1(2), 69-89.

Tabachnick, B. G., \& Fidell, L. S. (2001). Using multivariate statistics. Allyn and Bacon.

Ülger, K., \& İmer, Z. (2013). Probleme dayalı öğrenme (PDÖ) yaklaşımının öğrencilerin yaratıcı düşünme becerileri üzerine etkisi. Hacettepe Üniversitesi Ĕ̆itim Fakültesi Dergisi, 28(28-1), 382-392.

Wonder,J.\& Donovan, P. (1988). Whole brain thinking. Ballantine Books.

Yetim, A. A., \& Göktaş, Z. (2004). Öğretmenin mesleki ve kişisel nitelikleri. Kastamonu Ĕ̆itim Dergisi, 12(2), 541-550.

Yıldız, K., \& Yılmaz, B. (2020). Sınıf öğretmenliği adaylarının eleştirel düşünme ve yanal düşünme eğilimleri arasındaki ilişki. Bolu Abant İzzet Baysal Üniversitesi Eğitim Fakültesi Dergisi, 20(1), 335-353.

Yılmaz, B. (2017). Stnıf öğretmen adaylarının eleştirel düşünme ve yanal düşünme eğilimleri arasındaki ilişki. [Yayınlanmamış yüksek lisans tezi]. Abant İzzet Baysal Üniversitesi.

Yükseköğretim Kurulu [YÖK] (2018). Yeni Öğretmen Yetiştirme Lisans Programları. https://www.yok.gov.tr/kurumsal/idari-birimler/egitim-ogretim-dairesi/yeni-ogretmen-yetistirmelisans-programlari 


\section{EXTENDED ABSTRACT}

\section{Introduction}

The expression of thinking skills indicates an individual's capacity to think consciously in order to achieve a goal. The human brain has vertical thinking in the left hemisphere and lateral thinking in the right hemisphere. The concept of lateral thinking, which is related to generating new perceptions and ideas, was first used by De Bono in 1967. Although lateral thinking is similar to creative thinking in terms of producing unique perspectives, it differs from traditional thinking styles by being able to turn to different perspectives at the same time. Cognitive flexibility is defined as being aware of alternative solutions and willingness to use them. Based on the definitions of lateral thinking and cognitive flexibility in the literature, it is understood that both concepts would like the individual to think about alternative solutions. Teachers who may encounter many different situations in the classroom are expected to be individuals who can look at the events from different angles and produce various solutions. This study examines the relationship between the lateral thinking tendencies and cognitive flexibility skills of preschool and primary school teachers. Based on this purpose, the sub-objectives of the research are as follows:

1. Identifying pre-service teachers' lateral thinking tendencies and cognitive flexibility levels.

2. Identifying whether pre-service teachers' lateral thinking tendencies vary by gender.

3. Identifying whether pre-service teachers' tendency to lateral thinking differs according to the department they study at.

4. Identifying whether pre-service teachers' tendency to lateral thinking differs according to their grade.

5. Identifying whether pre-service teachers' tendency to lateral thinking differs according to the education level of the mother.

6. Identifying whether pre-service teachers' tendency to lateral thinking differs according to the education level of the father.

7. Identifying whether there is a relationship between pre-service teachers' tendency to lateral thinking and their cognitive flexibility levels

\section{Method}

This research was designed with relational screening model. The sample in the research consisted of pre-service teachers in the Department of Primary Education of a state university in the Marmara region. The data were collected in the spring semester of the 2018-2019 academic year. Simple random sampling method was used for data collection. 457 pre-service teachers participated in the research. Among the participants of the study, 216 of the pre-service teachers were studying in the field of classroom education, whereas 241 pre-service teachers were studying in the department of preschool education. The data of the study were collected using the Lateral Thinking Tendency Scale developed by Semerci (2016) and the Cognitive Flexibility Inventory developed by Sapmaz and Doğan (2013). In the study, which included 457 pre-service teachers studying in the Department of Primary Education, the suitability of the data set for normal distribution was examined firstly. Accordingly, the skewness and kurtosis coefficients of the data set were calculated. In addition, the Kolmogorov-Smirnov test was applied. It was found that the values obtained by dividing the skewness and kurtosis coefficients by their standard errors and the data set obtained as a result of the Kolmogorov-Smirnov test were in accordance with the normal distribution. Accordingly, it was decided that it was appropriate to use parametric tests in the analysis of the research data.

\section{Results}

It was found that the pre-service teachers' tendency for lateral thinking did not differ significantly by gender. This finding indicates that the lateral thinking tendencies of the female and male teacher candidates 
are similar. This finding is in line with the findings of different studies in the literature in which pre-service teachers' lateral thinking tendencies were examined. Based on the gender-related findings in studies that examine lateral thinking tendencies of both pre-service teachers and other university students, it can be said that the lateral thinking tendencies of women and men are similar. This gender-oriented finding can reveal that vocational education does not cause a differentiation in the lateral thinking tendencies of women and men. It was observed that the pre-service teachers' tendency to lateral thinking did not differ according to the department they were affiliated with. In other words, it was seen that the teacher candidates studying in the departments of classroom education and preschool education had similar lateral thinking tendency levels. In a similar way, it is thought that different teacher training undergraduate programs do not change pre-service teachers' tendency for lateral thinking. It was found that the pre-service teachers' tendency for lateral thinking did not differ significantly according to their grade level. However, although it does not make a significant difference, it can be seen that the pre-service teachers' lateral thinking tendency points increased from the first grade to the fourth grade. It was found that there was no significant difference between the teacher candidates' lateral thinking tendencies and the education level of their mothers and fathers. This finding is supported by the studies examining the relationship between critical thinking skills, problem solving skills, and cognitive flexibility skills, which are related to the lateral thinking skill, and the educational status of parents. For example, studies examining the critical thinking levels of pre-service teachers show that the educational status of parents does not make a significant difference. It was found that there was a high positive correlation between the lateral thinking tendencies and cognitive flexibility capacities of the pre-service teachers.

\section{Conclusion}

Studies point out that individual should tend to think laterally to use multiple perspectives. Teachers who encounter many students with different thinking skills should review their thinking styles and organize the learning environment accordingly in order to develop children's thinking skills. In addition, it is understood that the tendency for lateral thinking develops faster in young children. Based on this information, it can be said that the development of the thinking skills of pre-school teacher candidates, who will teach in the 3-6 age group, and primary school teacher candidates, who will take an active role in the education of children in the 6-11 age group, will contribute to the development of the thinking skills of their students. Therefore, conducting studies to reveal the awareness of pre-service teachers about the relationship between lateral thinking skills and cognitive flexibility will help improve the thinking skills of both preservice teachers and students by providing detailed information on this subject. 